\title{
Praxis-Software: erstmals weniger Installationen
}

\author{
In der Rangliste der Praxis-EDV- \\ Anbieter - zumindest in den Top Ten \\ - hat sich wenig geändert. Aber erst- \\ mals ist die Zahl der Installationen \\ rückläufig.
}

- Eine Arztpraxis ohne EDV-System scheint inzwischen eine Seltenheit zu sein, betrachtet man die aktuelle Installationsstatistik der Kassenärztlichen Bundesvereinigung (KBV). Denn die KBV meldet insgesamt 115440 Installationen von Praxis-EDV-Systemen (Stand 30.6.2010).

\section{Steigender Kooperationsgrad?}

Allerdings ist zum ersten Mal seit langem die Gesamtzahl der Installationen gesunken, und zwar um 2133 im Vergleich zum Vorjahr (damals zählte die KBV 117573 Installationen). Ein Grund dafür könnte ein steigender Kooperationsgrad sein. Die Anzahl der Vertragsärzte hingegen ist eher nicht gesunken, zumindest nach den aktuellen Zahlen der KBV, die allerdings nur einen Vergleich der Anzahl der Vertragsärzte in 2009 zu 2008 zulassen. Hier gab es einen leichten Zuwachs, nämlich von 136063 auf 137128 Vertragsärzte und -psychotherapeuten.

Das beliebteste EDV-System unter niedergelassenen Ärzten ist weiterhin Medistar, das im Vergleich zum Vorjahr seinen Marktanteil leicht auf 12,58\% erhöhen konnte. Insgesamt erreichte die Software 14524 Installationen, das sind 38 mehr als im Vorjahr. Auf dem zweiten Platz ist TurboMed mit 13365 Installationen und einem Marktanteil von $11,58 \%$, gefolgt von MCS-ISYNET mit 9022 Installationen und Albis on Win-

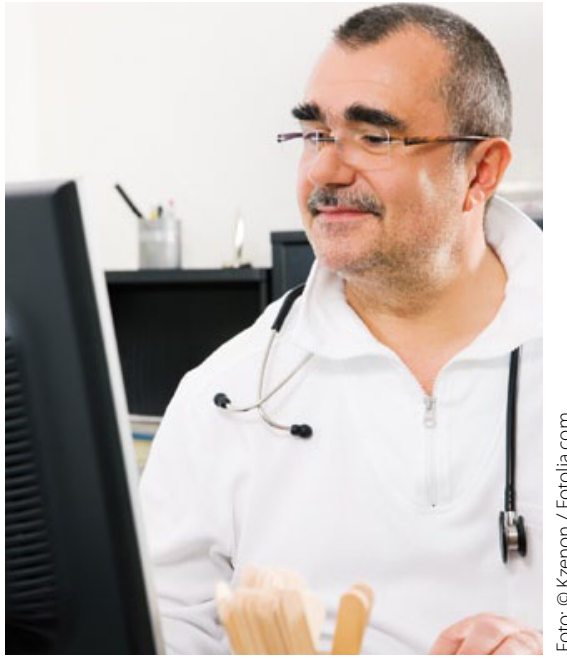

Inzwischen steht in nahezu allen Arztpraxen ein EDV-System zur Verfügung.

dows mit 7319 Installationen. Ebenfalls in die Top Ten schafft es Quincy Win von Frey ADV, und zwar auf Platz zehn mit 4169 Installationen.

Betrachtet man nur die Facharztgruppe der Allgemeinärzte, dann liegt TurboMed mit 4234 Installationen auf Platz eins, gefolgt von Medistar mit 3005 Installationen und DOCcomfort von medatiXX mit 2467.

REH =

\section{Ambulante Kodierrichtlinien}

\section{Zurückhaltende Zwischenbilanz}

\section{Nach den Erfahrungen der Praxis- Softwareanbieter fangen die nieder- gelassenen Ärzte erst langsam an, mit den neuen ambulanten Kodier- richtlinien zu arbeiten.}

— „Erst etwa drei Prozent der Ärzte arbeiten mit den Kodierrichtlinien", sagt Geschäftsführer Lars Wichmann. „Die Ärzte scheinen erst einmal abzuwarten." Auch bei dem genossenschaftlich organisierten Softwarehaus Duria gibt es erst vereinzelte Rückmeldungen, berichtet
Erich Gehlen von Duria. Das Softwareunternehmen medatixx kann noch überhaupt keine Aussage machen, da kaum Ärzte die AKR aktiviert hätten.

\section{Überschaubarer Aufwand}

Ganz anders sieht es bei der CompuGroup Medical aus. Dort arbeite schon jeder zweite Arzt mit den neuen AKR. Auch scheine sich der Aufwand in den Praxen in Grenzen zu halten, berichtet Pressesprecher Michael Franz von den ersten Rückmeldungen.
Der Forderung der KBV-Vertreterversammlung, dass die Kodierrichtlinien während der Übergangsphase einund wieder ausgeschaltet werden können, sind die meisten Softwarehäuser mittlerweile nachgekommen. Das Fehlen der Funktion hatte für viel Aufregung gesorgt, weil es hieß, dass, einmal aktiviert, sich die Kodierrichtlinien in der Übergangsphase nicht mehr zurückschalten lassen. Dies ist jetzt aber nach Angaben aus Praxis-EDV-Unternehmen ohne Probleme möglich. 